\title{
Developments for the System Identification Toolbox for MATLAB
}

\author{
Lennart Ljung \\ Department of Electrical Engineering \\ Linköping University, S-581 83 Linköping, Sweden \\ WWW: http://www.control.isy.liu.se \\ Email: ljung@isy.liu.se
}

March 3, 1999

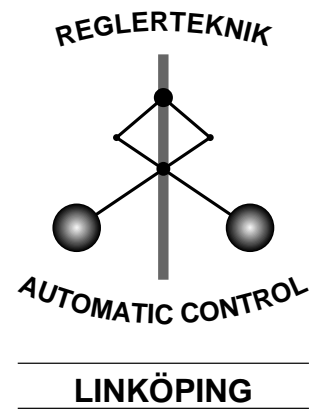

Report no.: LiTH-ISY-R-2102

For the IFAC Symposium on System Identification, Fukuoka, Japan, 1997

Technical reports from the Automatic Control group in Linköping are available by anonymous ftp at the address ftp.control.isy.liu.se. This report is contained in the compressed postscript file 2102.ps.Z. 



\title{
Developments for the System Identification Toolbox for MATLAB
}

\author{
Lennart Ljung
}

March 3, 1999

\begin{abstract}
In this contribution we describe some of the basic new features of MathWork's System Identification toolbox, version 4.0, which was released in May 1995. The main addition is a graphical user interface (GUI), which allows the user to perform identification, data and model analysis, as well as model validation by "click and mouse" operations. The ideas behind the GUI are explained and its relative merits compared to command driven operations are discussed.
\end{abstract}

Keywords: identification, software support, graphical user interface

\section{INTRODUCTION}

As pointed out, e.g., in (Ljung, 1993) and (Nagy, 1992) one can distinguish between three generations of identification software packages:

- The First generation is the batch routine period. During the 1960s, many (FORTRAN) subroutines were written for estimation of parameters in different model structures. This development took place at many universities and research inistitutes in parallel. The subroutines were in batch mode, and the obtained models had to be subjected to analysis using other batch programs.

- The Second Generation is the interactive identification package period. The next step started around 1970 when the different soubroutines for model estimation and model analysis were collected together with abetter user interface and direct graphical facilities (much like the way the LINPAC and EISPAC FORTRAN subroutines were linked together into mainframe MATLAB some decade later). The HELP facilities in this generation are syntax oriented.Many packages of this type have been created, 
and several of them are commercially available. One can say that the step from the first to the second generation meant a tremendous increase in efficiency for the user, but from a conceptual point, it was only just that: More user-friendly and efficient than the first generation numerical routines.

- The Third generation contains packages with decision support, advanced help and graphical user interaction. The development of new software techniques has opened up the possibilities to offer more thanjust passive numerical computations from an identification package. The third generation which is emerging right now is characterized by much more advanced interaction facilities as well as by knowledge absed system (KBS) techniques of various kinds. For the latter aspects, substantial experimentation has been reported, see (Nagy, 1992), (Nagy and Ljung, 1989), (Larsson and Persson, 1991) . For a survey, see (zuFarwig and Unbehauen, 1991).

Here we shall describe some features of MathWork's System Identification Toolbox (SITB), version 4. (to be used with MATLAB), (Ljung, 1995). The step from ver 3 to ver 4 is a step from the second to the third generation. A user interface, based on graphical interaction, has been added. This solves several of the "bookkeeping problems" discussed, e.g., in (Nagy, 1992) as well as giving the basis for more advanced help and support features.

\section{THE BASIC IDEAS BEHIND THE GUI}

What is the most pressing problem for a user of any interactive design/analysis package? Well, for a user, who is not a beginner, I believe that it is keeping track of what has been done. This is especially pronounced for System Identification applications, where quite a large number of tentative models are estimated and many aspects of these models are looked at. For the final decision about what model to use, one thus needs a good overview of the session.

A prime idea behind SITB ver4 has been to provide such an overview. This is accomplished by a Data and Model Summary Board (See the figure at the end of the paper) into which all created data sequences and models are automatically enetered. They are given default names, which the user easily may superseed. Double-clicking the icons associated with these model/data sets opens up a dialog box (TEXT INFO) with details and diaries about the variable. The current status of the Data and Model Summary Board is called a session. Sessions can be saved and reloaded at will. The four last sessions are kept under the File menu, for immediate access, similarly to, e.g., Words or Excel. This gives the user good possibilities to manage the identification process.

To further examine the models on the board, six views are available: Frequency response, Zeros and Poles, Transient response, Noise spectrum, as well as Residual analysis and Model Output Simulation comparisons.

All the basic operations on data (selection of data portions, decimation, detrending etc) as well as all estimation routines are accessed from menus in the main window, which in some cases opens up hierarchies of dialog boxes. All options available in the command mode are also accessable from the GUI, 
with the principle that they in should live a quiet life behind an "options" push button.

All View windows have the same menu that allows useful figure manupulations, such as scale choices, zoom facilities, linestyle choices etc.

The HELP system is organized so that pushing a help button in a dialog window opens up a help text that applies to the current context. The help system is then linked by hypertext links so that it should be easy to move around to get help support on different topics. The help system is written in HTML.

Finally, the GUI is a complement rather than an alternative: all functions can either be run in command mode or in GUI mode, and one can freely mix the two modes. The goal is, though, that the typical user should be able to run any application entirely in GUI mode if he or she prefers that.

\section{IMPLEMENTATION}

The whole GUI is implemented in MATLAB4 using the two basic functions uimenu and uicontrol. The program thus runs on any platform that is supported by MATLAB. All created models and data sets are stored as userdata of the different GUI-objcets, and are thus independent of the variables that live in the workspace. Import and export between the workspace and the GUI is easily handled be pushbuttons and commands. The size of the GUI-related code is about half the total size of the SITB code.

\section{SOME MORE NEWS IN SITB v4}

The new version of the Identification Toolbox also contains an implementation of the so called subspace identification algoritms, viz N4SID, see (Overschee and Moor, 1994), which is a most useful complement to traditional maximumlikelihood based methods. As a consequence, the start-up mechanism for blackbox parameterized state-space models (in canstart) has been changed to the N4SID method.

When dealing with estimation of time-continuous models, fitted to sampled data, it is valuable to allow various sampling schemes. The basic routine ms 2 th now supports both zeroth and first order hold sampling.

New routines for input design have been added to the toolbox, as well as for model order reduction. 


\section{References}

Larsson, J.E. and P. Persson (1991). An expert system interface for an identificationprogram. Automatica 27(6), 919-930.

Ljung, L. (1993). Identification of linear systems. In: CAD for Control Systems (D. A. Linkens, Ed.). Chap. 6, pp. 147-165. Marcel Dekker. New York.

Ljung, L. (1995). The System Identification Toolbox: The Manual. The MathWorks Inc. 1st edition 1986, 4th edition 1995. Natick, MA.

Nagy, P. (1992). Tools for Knowledge-Based Signal Processing with applications to System Identification. PhD thesis. Dept of Electrical Engineering, Linköping University. Linköping, Sweden.

Nagy, P. A.J. and L. Ljung (1989). An intelligent tool for system identification. In: IEEE Control Systems Society Workshop on Computer-Aided Control System Design (CACSD). Tampa, FL. pp. 58-63.

Overschee, P. Van and B. De Moor (1994). N4SID: subspace algorithms for the identification of combined deterministic-stochastic systems .. Automatica, (Special Issue) 30(1), 75-93.

zuFarwig, H. M. and H. Unbehauen (1991). Knowledge-based system identification. In: Proc. IFAC Symposiumon Identification and System Parameter Estimation. Budapest. pp. 20-28. 